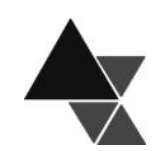

\title{
Alimentação do escolar: percepção de quem prepara e oferece as refeições na escola
}

\author{
Tatiana Yuri Assao ${ }^{1}$, Marcia Faria Westphal ${ }^{2}$, Cláudia Maria Bógus ${ }^{2}$, \\ Ana Maria Cervato-Mancuso ${ }^{3}$
}

O objetivo da pesquisa foi identificar as percepções vinculadas à alimentação escolar entre merendeiras de escolas públicas do município de Guarulhos (SP). Tratou-se de um estudo descritivo com abordagem qualitativa. Participaram 22 merendeiras das 13 instituições selecionadas, dentre 63 escolas do ensino fundamental. Para coleta dos dados optou-se pela técnica do grupo focal. As informações obtidas foram gravadas, transcritas e submetidas à análise de conteúdo. As percepções das merendeiras sobre alimentação escolar apareceram vinculadas às características do ambiente escolar e do alimento. As deficiências de espaço físico, equipamentos e materiais foram associados às dificuldades no desenvolvimento do trabalho e, consequentemente, na preparação e distribuição de uma alimentação adequada. A alimentação escolar, de acordo com esses profissionais, deveria ser nutricionalmente adequada e composta por gêneros de qualidade. As merendeiras possuem um papel importante na alimentação escolar, mas são poucas as oportunidades que lhes são oferecidas para interferir em algumas questões que percebem inadequadas. A atuação desses profissionais acaba se restringindo às ações operacionais, visto que outros atores e as próprias merendeiras, não percebem o espaço existente para ampliar a sua atuação na educação nutricional.

Palavras-chave: alimentação escolar, educação alimentar e nutricional, pesquisa qualitativa, programas e políticas de nutrição e alimentação.

\section{School feeding: perception of those who prepare and offer the meals at the school}

This study aim to identify the perceptions linked to school feeding by the school meal cooks of public schools from the city of Guarulhos, SP. It is a descriptive type study with a qualitative approach. Twenty-two school meal cooks from the 13 institutions selected, among the 63 elementary school, participated. For data collection it was opted to use the focal group technique. The information obtained was recorded, transcribed and submitted to content analysis. The school meal cooks perceptions about the school feeding appear linked to the characteristics of the school environment and of the food. The lack of physical space, equipment and materials were associated to the difficulties in the development of the work and consequently in the preparation and distribution of adequate eating. School feeding according these professionals should be nutritionally proper and composed by items of quality. The school meal cooks have an important role in school feeding, but few opportunities are offered to them to interfere in some matters that they consider inappropriate. The performance of these professionals end up being restricted to the operational actions, seeing that other players and the school meal cooks themselves do not see existing room to enlarge their performance in nutritional education.

${ }^{1}$ Doutora em Ciências, Departamento de Nutrição da Faculdade de Saúde Pública (FSP), Universidade de São Paulo (USP). Correspondência: Tatiana Yuri Assao. Av. Dr. Arnaldo, 715 - Cerqueira Cezar. CEP 01246-904, São Paulo, SP. Telefone: 3061-7705. E-mail: tatiassao@usp.br.

${ }^{2}$ Docente do Departamento de Práticas de Saúde Pública, FSP (USP).

${ }^{3}$ Docente do Departamento de Nutrição, FSP (USP). 
Key-words: school feeding, nutritional and food education, qualitative survey, food and nutrition policies and programs.

\section{INTRODUÇÃO}

A alimentação das crianças em idade escolar reflete as práticas alimentares adotadas por suas famílias e as oferecidas na escola, e estão condicionadas a vários fatores, entre os quais as condições de produção e distribuição da alimentação nesse espaço. Nesse sentido, estão em pauta não somente os cardápios e sua adequação aos hábitos alimentares culturalmente estabelecidos na região, mas também o ambiente físico e social em que se produz e oferece a alimentação ${ }^{[1]}$.

De acordo com Diez-Garcia [2], além das características dos alimentos e dos serviços de alimentação, o ambiente $\mathrm{e}$ as circunstâncias de produção e distribuição, também exercem influência na escolha alimentar. O comportamento alimentar é complexo, inclui determinantes internos e externos ao sujeito, leva em conta as práticas alimentares que vão desde os procedimentos relacionados à seleção dos alimentos, sua preparação e seu consumo propriamente ditos, incluindo outros valores simbólicos associados à alimentação [3].

Nesse sentido, Quaioti \& Almeida ${ }^{[4]}$ ratificam que o comportamento alimentar humano reflete interações entre o estado fisiológico, o estado psicológico e as condições do local em que o indivíduo se alimenta. A capacidade para controlar a ingestão requer mecanismos especializados para harmonizar informações fisiológicas do meio interno com informações nutricionais do ambiente externo. As informações do meio interno dizem respeito a neurotransmissores, hormônios, taxa metabólica, estados do sistema gastrointestinal, tecidos de reserva, formação de metabólitos e receptores sensoriais. As informações do meio externo dizem respeito a características dos alimentos - sabor, familiaridade, textura, composição nutricional e variedade, e características do ambiente - oferta ou escassez de alimentos, localidade, estrutura e equipamentos disponíveis, assim como crenças sociais, culturais e religiosas.
Assim como os aspectos internos e externos à alimentação escolar influenciam o comportamento alimentar das crianças, os atores sociais envolvidos no preparo e distribuição dos alimentos podem influenciar nos processos de educação nutricional e, portanto, possuem papel relevante neste contexto. Entre os sujeitos que estão diretamente ligados ao momento da alimentação, destacam-se as merendeiras. Estes profissionais têm sob sua responsabilidade a tarefa de compreender todo o processo de produzir e distribuir as refeições, além do seu papel na promoção da educação nutricional [5,9]. Teo et al. [7] em um estudo com merendeiras de escolas estaduais de Chapecó $\mathrm{SC}$, observaram que o potencial desses profissionais para a educação em saúde permanecia inexplorado e que alguns nem percebiam essa possibilidade. Os pesquisadores justificavam essa posição sobre o papel desses profissionais na educação nutricional e na alimentação escolar pela satisfação que expressaram em exercer a função, por se relacionarem continuamente e terem grande vínculo com as crianças e principalmente pelo desejo de maior participação e integração com os outros atores escolares.

Com o fato de ter sido estabelecido um modelo de distribuição de alimentos diferenciado - o autosserviço - as merendeiras teriam mais oportunidades de contato e de influência nas escolhas de alimentos dos escolares. As percepções desses profissionais tornam-se relevantes na avaliação do sistema e para o encaminhamento de soluções para os problemas existentes. Face o exposto, este estudo procurou identificar as percepções vinculadas à alimentação escolar das merendeiras de escolas públicas do município de Guarulhos (SP).

\section{MÉTODO}

O estudo do tipo descritivo com abordagem qualitativa foi desenvolvido no município de Guarulhos nos anos de 2007 e 2008, nas escolas públicas municipais. 
Localizado na Região Metropolitana de São Paulo, Guarulhos contava com 1.236.192 habitantes no censo populacional de 2006 em sua área urbana e com 40.715 estudantes matriculados nas escolas municipais de educação fundamental, caracterizandose como um grande centro urbano ${ }^{[8]}$.

O município, na época da pesquisa, apresentava um universo de 63 unidades escolares de ensino fundamental. Destas escolas, $80 \%$ pertenciam às regiões mais excluídas, $10 \%$ às de mediana exclusão e $10 \%$, às unidades de menor exclusão.

Como interessava para o estudo conhecer a influência do diferencial socioeconômico existente entre os estudantes que frequentavam as diferentes escolas municipais de Guarulhos, foi realizada a combinação dos seguintes indicadores para a seleção por pareamento:

1. Estratos de exclusão socioeconômico da região onde as escolas se localizavam, conforme dados do diagnóstico municipal da Secretaria de Saúde: exclusão social maior (índice entre $-1,0$ e $-0,5$ ), exclusão mediana (índice de $-0,49$ e 0,0 ) e exclusão menor (índice entre 0,0 e 1,0);

2. Processo produtivo predominante nas áreas onde as escolas se localizavam (urbana com atividades de comércio e serviços, urbana com agricultura familiar e rural com propriedades agrícolas - média e grande propriedade);

3. Tamanho das escolas: pequena (até 500 estudantes), média (entre 500 e 900 estudantes) e grande (com mais de 900 estudantes).

A seleção das unidades escolares obedeceu a critérios estratégicos de modo a garantir a proporcionalidade dos indicadores. A partir da combinação desses três indicadores selecionou-se 13 escolas, cada uma atendendo a três critérios combinados (Quadro).

Todas as merendeiras das 13 escolas selecionadas, totalizando 26 profissionais, foram convidadas a participar da pesquisa.

Para coleta dos dados optou-se pela técnica do grupo focal. O grupo focal é uma técnica que permite a obtenção de dados de natureza qualitativa a partir de sessões grupais em que as pessoas que compartilham um traço comum discutem vários aspectos de um tema específico [?]. Trata-se de uma discussão focada em tópicos, numa interação entre os participantes e o pesquisador [10,11]. É bastante adequada para a identificação de conceitos, crenças, percepções, expectativas, motivações e necessidades de um grupo [12]. Partindo do pressuposto que as percepções são socialmente construídas, a técnica torna-se interessante por oferecer possibilidades para se pensar coletivamente uma temática que faz parte da vida das pessoas que estão reunidas [9].

De acordo com as recomendações para aplicação da técnica, os grupos são constituídos por cerca de 6 a 15 integrantes, desta forma as merendeiras seriam divididas em dois grupos, selecionadas casualmente [9]. As aplicações da técnica foram realizadas por equipes experientes na condução, respeitando todos os requisitos operacionais necessários para a técnica desde a seleção, composição e recrutamento dos participantes; local adequado; número de encontros e duração dos grupos; condução dos grupos; registros e transcrição dos dados [9,10,12,13]. De acordo com as recomendações, os encontros foram conduzidos por um moderador, com auxílio de um observador, que encorajava os participantes a expressarem livremente suas opiniões, sentimentos e pareceres sobre a questão em estudo a partir de um roteiro, em que a questão norteadora estava associada ao entendimento da equipe quanto à alimentação escolar.

Os comentários dos grupos foram gravados, posteriormente transcritos e submetidos à Análise de Conteúdo, de acordo com a técnica proposta por Bardin [14]. Desta forma, submeteu-se o material resultante dos grupos a três etapas: pré-análise, exploração do material e tratamento dos resultados e interpretação. $\mathrm{Na}$ pré-análise, realizou-se a leitura flutuante, que permitiu uma visão global dos dados coletados. A exploração do material foi feita por uma análise detalhada que possibilitou a identificação das unidades de registro e construção das categorias temáticas. E no tratamento dos resultados e interpretação, o conteúdo foi analisado e discutido com o auxílio do referencial teórico sobre o tema ${ }^{[14,15]}$.

Visando o anonimato dos participantes, para a apresentação das frases que expressavam conteúdos relacionados a temas específicos - resultados - criouse uma identificação. Assim, "M" significa 
"merendeira", seguido por um número de identificação dos sujeitos, uma vez que não se identificou as frases com os nomes próprios dos mesmos, e uma letra minúscula ("a" ou "b") que as distinguiam de acordo com o grupo focal em que participaram, dado que os profissionais foram divididos em duas turmas na coleta dos dados.
A pesquisa considerou os princípios éticos, sendo aprovada pelo Comitê de Ética em Pesquisa da Faculdade de Saúde Pública (FSP) da Universidade de São Paulo (USP). Respeitou a Resolução do Conselho Nacional de Saúde - CNS 196/96, que regulamenta estudos envolvendo seres humanos, possibilitando aos sujeitos manifestarem sua anuência à participação na pesquisa mediante consentimento livre e esclarecido.

\begin{tabular}{|cccc|}
\hline Escola & Índice de Exclusão Social (IEx) $^{1}$ & Região $^{2}$ & Tamanho $^{3}$ \\
\hline 1 & IEx maior & Urbana & Grande \\
2 & IEx maior & Urbana & Grande \\
3 & IEx maior & Urbana & Média \\
4 & IEx maior & Urbana com agricultura familiar & Grande \\
5 & IEx maior & Urbana com agricultura familiar & Média \\
6 & IEx maior & Urbana com agricultura familiar & Média \\
7 & IEx maior & Rural agrícola & Grande \\
8 & IEx maior & Rural agrícola & Grande \\
9 & IEx maior & Rural agrícola & Pequena \\
10 & IEx mediano & Urbana & Grande \\
11 & IEx mediano & Urbana & Média \\
12 & IEx menor & Urbana & Média \\
13 & IEx menor & Urbana & Pequena \\
\hline
\end{tabular}

${ }^{1}$ A Secretaria de Saúde de Guarulhos realizou um estudo de caracterização do município utilizando dados secundários e por ocasião da pesquisa contava com um diagnóstico socioeconômico, de saúde e ambiental do município geoprocessado por sub-regiões administrativas de saúde, permitindo conhecer as características dos diferentes territórios em relação a questões socioeconômicas, ambientais e de saúde.

2 A divisão administrativa da Secretaria da Educação não era a mesma da Saúde, utilizando como critério de caracterização socioeconômica a localização das escolas em área urbana, com processo produtivo principalmente baseado em atividades comerciais e serviços, e área urbana, com processos produtivos baseados em agricultura familiar e área rural, com processos produtivos baseados em produção agrícola em médias e pequenas propriedades.

3 Ainda era importante neste pareamento o tamanho das escolas, pois esta variável pode fazer diferença na aprendizagem e em outras atividades relacionadas a ela como a nutrição e a educação nutricional.

Quadro. Descrição das escolas segundo Índice de Exclusão Social das regiões, processo produtivo predominante no local e o tamanho. Guarulhos, 2007.

\section{RESULTADOS E DISCUSSÃO}

Dentre as 26 merendeiras convidadas, participaram do estudo 22, que foram divididas em dois grupos focais de 11 participantes, com duração média de uma hora e trinta minutos cada.
As percepções do grupo sobre a alimentação escolar resultaram em duas categorias:

\section{Alimentação escolar associada ao ambiente}

Quando incentivadas a falar sobre a alimentação escolar, observou-se que os comentários 
sobre $\mathrm{o}$ ambiente, principalmente a infraestrutura destinada ao preparo dos alimentos, foi um tema muito presente nos discursos. As características do ambiente, como a disponibilidade de espaço físico, dos equipamentos e dos materiais, na percepção desses profissionais, estão diretamente associadas à alimentação escolar. A ausência de investimentos nesses itens pode repercutir em dificuldades no desenvolvimento do trabalho e consequentemente no processo de ofertar alimentos adequados, de acordo com os objetivos da alimentação escolar do município, como observado nos discursos. A gestão descentralizada do Programa Nacional de Alimentação Escolar (PNAE) não prevê investimentos em nível local para o provimento das instalações, equipamentos e do pessoal para o preparo e distribuição das refeições. Os recursos repassados do governo federal para o municipal destinam-se exclusivamente à compra de gêneros alimentícios, cabendo ao município arcar com a responsabilidade de disponibilizar infraestrutura mínima para a preparação das refeições [16, 17].

O espaço é restrito em muitas das cozinhas, fazendo com que as merendeiras coloquem os alimentos em locais que não são adequados para estocagem. Os gêneros que necessitam de refrigeração muitas vezes têm que ser preparados no momento do recebimento ou congelados. O espaço físico de muitas cozinhas, segundo algumas delas, é limitado e em algumas há somente uma pia pequena, são copas que funcionam como cozinhas. Assim se manifestaram as merendeiras sobre as deficiências do espaço físico:

"Está faltando estrutura para trabalhar (...) simplesmente não têm condicões de se trabalhar, a cozinha é pequena, têm dias que não têm nem estoque, têm que improvisar colocando em cima de armário, arrumar prateleira, se virar!" (M3a).

"Não temos geladeiras suficientes, não temos espacos para armazenar os legumes (...), às vezes a gente acredita que a escola vai ser reformada, porque é um 'bequinho' para guardar tudo o que precisamos, como se vai conservar? Cenoura, batatas, abobrinha... não temos espaço para conservar, então não basta chegar lá e olhar o cardápio...” (M3a).

Mencionam que há escolas que não têm esses problemas, por que sua construção mais recente previu um espaço mais adequado, mas sugerem que muitas outras sejam reformadas para melhorar a infraestrutura necessária para o fornecimento de uma alimentação adequada:

"O espaço fisico é uma necessidade, sei que têm escolas por ai que são maravilhosas, principalmente ao nivel que chegamos hoje, de self-service, de manuseio de alimentos, mas precisam passar por uma reforma. A questão do espaço físico, precisa dar condiçoes! Deveriamos ter melhores condicooes nas ferramentas, de aparelhos, a cozinha geralmente é pequena, tem poucos freezers, é muito gênero para pouco material. Chega um monte de verdura e você empilha tudo na cozinha. A gente não tem onde armazenar, a dispensa é pequenininha, chega aquele monte de alimentos a gente tem que empilhar tudo. As condições na minha escola são ruins por causa do espaço físico e falta de materiais, faca, liquidificador, essas coisas que a gente precisa usar no dia a dia" (M4a).

"A minha escola é grande, mas falta aumentar o tamanho da cozinha, a escola tem muitos alunos e só tem dois freezers e uma geladeira para guardar tudo. Faltam equipamentos e materiais para o dia a dia como: facas e panelas para o uso no nosso trabalho... E ter menos cobrança da nossa supervisão, que pede para não deixar estragar e vencer los alimentos), seguir o cardápio, mas não dá, essa parte dos equipamentos precisa melhorar" (M1a).

Nesse sentido, outros estudos que se propuseram avaliar o programa também identificaram essa deficiência. Santos et al. ${ }^{[16]} \mathrm{em}$ uma pesquisa em escolas nos municípios do interior da Bahia cujo objetivo era identificar os obstáculos e oportunidades que incidiam sobre a implementação descentralizada do PNAE de 1995-2002, os gestores entrevistados apontaram como principal obstáculo a deficiência da infraestrutura. Mascarenhas \& Santos ${ }^{[18]}$ por meio de estudo que se propôs a analisar o valor nutricional e o custo da alimentação de estudantes de escolas públicas em zona rural e urbana em um estado também da Bahia, observaram que a falta de infraestrutura, como espaços físicos adequados e equipamentos básicos, principalmente refrigeradores, em algumas escolas, impossibilitava o armazenamento dos alimentos perecíveis, o que influenciava a composição do cardápio oferecido aos alunos, uma vez que não eram comprados com regularidade. Martins et al. ${ }^{[19]} \mathrm{em}$ escolas públicas de ensino fundamental de Piracicaba (SP) verificaram que para aumentar a aceitabilidade da alimentação escolar seriam fundamentais ações de educação nutricional e de qualificação de toda a comunidade escolar, associadas a investimentos no ambiente, na infraestrutura de produção e distribuição da alimentação. 
Valeriani [20] acredita que há um desconhecimento das necessidades das cozinhas escolares, pois em um estudo que avaliou o sistema de gestão do Programa de Alimentação Escolar em Goiás, observou a ausência de investimento em equipamentos de necessidades primárias.

Visto a atividade que as merendeiras desempenham nas escolas, de manipular, preparar e distribuir as refeições visando à promoção da saúde de escolares por meio da suplementação alimentar, muito se fala em capacitar esses profissionais. Por serem os responsáveis pelo preparo das refeições, há uma grande preocupação para que esses detenham conhecimentos e técnicas principalmente de boas práticas de higiene e manipulação dos alimentos. Porém é necessário investigar e atuar sobre as suas condições de trabalho, no contexto global de fatores que interferem na alimentação escolar, tanto os individuais, como os coletivos, os comportamentais e também os ambientais, que de alguma forma condicionarão as práticas dos profissionais que atuam no sistema [5].

A portaria interministerial no 1.010 , de 8 de maio de 2006, que institui as diretrizes para Promoção da Alimentação Saudável nas Escolas, estabelece que entre os eixos prioritários está o estímulo à implantação de boas práticas de manipulação de alimentos nos locais de produção e fornecimento de serviços de alimentação do ambiente escolar, sendo necessário sensibilizar e capacitar os profissionais envolvidos com alimentação na escola para produzir e oferecer alimentos mais saudáveis. Aponta que para alcançar a alimentação saudável no ambiente escolar deve-se conhecer, fomentar e criar condições para a adequação dos locais de produção e fornecimento de refeições às boas práticas para serviços de alimentação [21].

Desta forma, um ambiente com espaço físico, equipamentos e materiais adequados possibilita melhor desempenho do trabalho dos profissionais, que inclui o cumprimento do cardápio planejado e principalmente o fornecimento da alimentação escolar de forma adequada. Condições precárias dos ambientes de produção das refeições, como as mencionadas por algumas merendeiras de algumas escolas de Guarulhos, podem acabar limitando a composição e execução dos cardápios, além de oferecer riscos de contaminação das preparações produzidas ${ }^{[1]}$.
As questões relacionadas à estrutura estão intimamente ligadas à administração do programa e as unidades escolares. A sua deficiência, associada a outros problemas como, por exemplo, o de abastecimento, compromete a qualidade do serviço e das relações entre os gestores e usuários, o que consequentemente gera reclamações quanto ao desenvolvimento do cardápio proposto. Os profissionais, de algumas escolas do município, muitas vezes são pressionados pelo dever de cumprir um cardápio estabelecido em condições inadequadas para sua viabilização [22]. Isso pode ser observado nos comentários das merendeiras:

"Aqui, por exemplo, só temos dois freezers... dois e uma geladeria pequena... quando chega outras coisas, tipo salsicha, não tem espaço para colocar as verduras, nós cozinhamos o espinafre, congelamos, para poder segurar mais tempo, para usar na outra semana...e quando têm duas, que vem da Central de Abastecimento, você tem que conferir a mercadoria e olhar porque às vezes eles entregam estragado... (M2b). Tem esse problema, então têm que olhar tudo, verduras, salsinha (está amarela), mamão todo amassado...”(M1b).

Reconhecem a mudança positiva em relação à alimentação escolar operada no município, mas indicam que ainda muitas mudanças estruturais precisam ser operadas para continuar o processo de oferta de uma alimentação adequada para os escolares de Guarulhos.

"Deixa en fazer uma observação? De duas gestões para cá, teve uma revolução na parte educacional, principalmente a merenda escolar. Para melhor! Dos dezoito anos que eu tenho de merenda está excelente! Só que está faltando estrutura para se trabalhar, Guarulhos tem muitas escolas novas, estão lindas... eu trabalho numa escola em que a cozinha é pequena, eu tenho uma geladeira pequena, só que aos sábados eu vou para o Perseu, uma escola enorme, cheguei lá fiquei encantada com a cozinha: três freezers, duas geladeiras, um monte de bacia, então o que está precisando na rede é dar uma atenção melhor para as escolas antigas, porque com esse cardápio, com esse negócio de self-service, simplesmente não têm condiçôes de se trabalhar, e têm dias que não têm nem estoque... têm que improvisar colocando em cima de armário, arrumar prateleira, se virar!" (M3a).

Essas observações, especialmente a última, expressa uma preocupação com a estrutura física oferecida para o armazenamento e preparo das refeições oferecidas às crianças através de práticas inovadoras como o autosserviço. 


\section{Alimentação escolar associada ao alimento}

O cardápio e os alimentos necessários para colocá-lo em prática de forma satisfatória foi outra categoria identificada, e esse tema esteve muito presente nos comentários das merendeiras. Para esses profissionais $\mathrm{o}$ cardápio tem um significado importante, sentem-se satisfeitos ao observarem que as refeições oferecidas estão adequadas nutricionalmente e principalmente que estão sendo aceitas pelas crianças, um ponto positivo do novo sistema (autosserviço).

Percebeu-se uma preocupação com os alimentos oferecidos, para uma maior aceitação pelos alunos:

"Eles chegam no balcão e pergunta: Tia qual é o cardápio hoje? O que vai ter hoje de comida? Tia você não vai escrever pra nós na lousa o cardápio?" (M2b). "O que estou faz̧endo (refere-se à troca de uma das preparações do cardápio) épro bem das crianças (M4b).”

"Essa coisa dos alimentos, é uma coisa que as crianças também percebem. Eles não querem, jogam fora. $\mathrm{Na}$ fase do arroz ruim, cada dia que passava a criançada queria menos arroz, aí fui diminuindo. Eles enchiam o prato de feijão $e$ colocavam um pouquinho de arro\%, por quê? O cheiro do arro\%! A gente caprichava, mas não é a mesma coisa, o cheiro do arroz! Eles sentiam: Ai tia não quero esse arroz! Ai a gente enchia de feijão" (M2b).

Frente a essa preocupação com a qualidade dos alimentos, as merendeiras mencionam alguns obstáculos que impedem o cumprimento satisfatório do cardápio planejado até a oferta dos alimentos. Além da insuficiência do espaço físico e equipamentos, já citados, referiram a deficiência no processo de planejamento do cardápio e abastecimento dos gêneros.

A qualidade dos gêneros é um tema recorrente nos depoimentos, pois frequentemente recebem os alimentos em condições não adequadas para o consumo, o que prejudica as características naturais dos alimentos:

"Infelizmente têm que aceitar, têm que se virar, só se tiver estragado não recebemos..." (M2a).
"Nos últimos quatro ou cinco meses a verdura não está de acordo, outro dia entregaram uma pera totalmente verde, e congelada, ai quando esperamos amadurecer e servimos não tinha nem mais sabor, então ultimamente nada tem estado de acordo" (M3b).

As inadequações na rotina do abastecimento também foram apontadas em um estudo de Spinelli \& Canesqui [23], principalmente quanto aos alimentos perecíveis como hortaliças e frutas.

Somada a essa observação, as merendeiras ressaltam também que os profissionais responsáveis pela elaboração do cardápio necessitam atentarem-se as características e qualidade dos alimentos:

"Não basta chegar lá e olhar o cardápio, têm que pensar o que vai estragar primeiro. Além disso, teve alimentos que nós tivemos que devolver porque não estava em condiçoes (...) a marca do feijão horrivel, têm coisas que não dá pra aceitar, isso é um problema sério (...), tem supervisora, qualquer pessoa que visse aquele feijão, não aceitaria” (M3a).

Percebe-se que o processo de compra e abastecimento dos gêneros que compõem o cardápio da alimentação escolar ocorre por meio de licitações, assim as empresas fornecedoras, apesar de oferecerem um custo atraente, frequentemente não atendem às expectativas quanto à qualidade dos gêneros. Dessa forma, as merendeiras também devem estar aptas para avaliar os alimentos entregues e por vezes não aceitar se estiverem comprometidos. Nas falas surgem observações quanto à qualidade dos alimentos, como o feijão, as carnes e as verduras, que frequentemente chegam às escolas em condições comprometidas, assim, as merendeiras supõem não haver supervisão adequada.

Bezerra [24] ao estudar as representações e práticas vinculadas à merenda em uma escola pública do ensino fundamental em Fortaleza constatou que decorrente das limitações, principalmente de fundos, os principais critérios de definição sobre o que comprar eram: os produtos de menor preço e nem sempre os de melhores características nutricionais, qualidade e mais aceitável pelas crianças.

A elaboração do cardápio é realizada pelas nutricionistas, porém observaram-se frequentes alterações realizadas pelas merendeiras: 
"Ele é elaborado aqui, têm as nutricionistas, que todo mês elaboram um cardápio novo e manda pra gente, mas no rodapé dos cardápios existem milhares de alteraçoes, porque se não tem algum gênero cabe à cozinheira modificar aquilo ali... têm alimentos como brócolis que estraga então têm que alterar no cardápio"(M1a).

"Vamos supor que a escarola está sendo substituida pela cenoura mas é na hora que você recebe que você vai saber o que será trocado para o cardápio da semana e é assim. Ai entra sua autonomia para modificar e eu vou falar uma coisa para vocês, o que está mais acontecendo por ai é modificação em cardápio mesmo porque on você modifica on você perde o produto"(M3a).

Porém, percebe-se que essa troca, apesar de frequente, não é do cardápio como um todo, mas de algumas preparações, geralmente necessárias devido à falta de algum gênero e principalmente pela qualidade dos alimentos recebidos para o preparo das refeições.

"De repente acabou o arroz, faz macarrão! E como a gente já tem todo material no estoque então se faltar alguma coisa a gente vai lá e faz outra coisa" (M2a).

"Mas se a gente sabe que uma salada vai estragar a gente troca, mas o cardápio não! Se a gente vai trocar é porque tem uma necessidade... não porque a gente quer, é pelo que dá para salvar, às vezes chega abobrinha, brócolis, alface, o que você vai pegar primeiro? O que estraga primeiro! É o brócolis... Já chegamos até ter que devolver, quando nós recebemos um fruta que está quase estragando nós mandamos de volta" (M4a).

Essa possibilidade de adaptações e manejo do cardápio também foi observada em outras pesquisas $[6,23]$. Embora exista um planejamento central, de responsabilidade da administração municipal ou estadual, que nem sempre contam com um quadro de nutricionistas suficientes para atender tal demanda, é localmente que as decisões operacionais são tomadas [25]. Assim, a participação das merendeiras e demais profissionais que trabalham diariamente na escola é importante na escolha de preparações que compõem o cardápio, considerando a convivência diária com os alunos e, consequentemente, o conhecimento dos seus hábitos alimentares. No entanto, o planejamento do cardápio é uma atividade inerente ao profissional de nutrição habilitado, o qual, segundo o Fundo Nacional de Desenvolvimento da Educação (FNDE) [26], deve assumir responsabilidade técnica da alimentação escolar, a fim de garantir a adequação às necessidades nutricionais, às faixas etárias e ao perfil epidemiológico dos escolares [6].

Se por um lado, as merendeiras não participam da elaboração do cardápio, por outro, elas reconhecem que a alimentação na escola representa a oferta de refeições nutricionalmente adequadas, compostas por gêneros alimentícios de qualidade e que tenham aceitabilidade por parte das crianças. Além disso, consideram que oferecer condições ambientais adequadas para a preparação das refeições é parte da alimentação escolar. Essas percepções estão relacionadas ao trabalho que realizam dado que detém grande parcela de ações operacionais. Verificou-se, entretanto, a ausência do reconhecimento do potencial educativo destas ações que, talvez, também não seja reconhecido e estimulado pelos gestores locais do Programa.

No cuidado da saúde da criança a alimentação é um aspecto fundamental para a promoção de sua saúde. Além de atender às necessidades nutricionais, a alimentação envolve práticas sociais, abordadas por múltiplas perspectivas, compreendidas desde a seleção, o consumo, a preparação, a distribuição e a ingestão dos alimentos, além da formação dos comportamentos alimentares saudáveis [27]. Toral \& Slater ${ }^{[28]}$ afirmam que o comportamento alimentar é determinado por diversas influências, que incluem os aspectos nutricionais, econômicos, sociais, culturais, ambientais e psicológicos que cercam o indivíduo ou a coletividade. Desta forma, o ambiente escolar assume um papel protagonista na construção dos hábitos alimentares das crianças.

Neste contexto, pode-se afirmar que as merendeiras, além da importante atribuição que envolve todo o preparo e distribuição da alimentação, tornam-se atores principais também no processo de promoção dos hábitos alimentares adequados no cenário escolar. Ao desenvolverem suas atividades, estes profissionais conhecem cada criança, como estes se comportam no grupo no momento da alimentação, os alimentos que aceitam e rejeitam, como se portam à mesa, tendo a oportunidade de orientá-los, contribuindo para a construção de hábitos alimentares adequados, assegurando às merendeiras relevante potencial para a educação em nutrição [5,7].

Aliado a função de ofertar um cardápio variado e nutricionalmente equilibrado, a merendeira, que prepara e distribui a alimentação escolar, é um 
profissional imprescindível para utilização da alimentação escolar como espaço permanente de aprendizado [6].

Teo et al. [7] em uma pesquisa com merendeiras de escolas estaduais, semelhantemente, verificaram que as funções desses profissionais nessas instituições restringiam-se à rotina de produção das refeições, preocupando-se com o consumo dos alimentos, tornando a sua prática pouco educativa. Esse cenário também foi percebido em instituições de educação infantil. Silva et al. [29] ao investigarem as práticas dos agentes profissionais, responsáveis pelos cuidados diários das crianças, como cuidados de higiene, oferta da alimentação e promoção de atividades pedagógicas, constatou uma significativa preocupação em oferecer a alimentação às crianças, porém o momento das refeições frequentemente não era visto como possibilidade de intervenção de educação nutricional.

Interessante ressaltar que, historicamente, o cargo da merendeira esteve atrelado à operacionalização do serviço de alimentação, com ênfase principalmente, aos aspectos nutricionais e de higiene das refeições, condizentes às características do programa que por um período privilegiou o atendimento aos aspectos biológicos da alimentação, subestimando os outros aspectos sociais que envolvem $\mathrm{o}$ ato de alimentar-se, assim como as suas possibilidades pedagógicas. Porém, atualmente, as novas diretrizes do Programa de Alimentação Escolar, ao destacarem a promoção de hábitos alimentares saudáveis e o reconhecimento da sua dimensão pedagógica, possibilitam maior visibilidade do desenvolvimento de atividades promotoras de saúde por meio das merendeiras. Isso significa entender o papel destes profissionais no coletivo escolar, redimensionado de modo a possibilitar a sua integração à equipe educativa nas atividades promotoras de saúde [5]. Contudo, constatou-se que para o grupo, o reconhecimento das suas potencialidades para além de preparar e distribuir uma alimentação adequada, a educação em nutrição no âmbito escolar, ainda não foi incorporada.

\section{CONSIDERAÇÕES FINAIS}

A alimentação engloba várias dimensões. Além do próprio alimento, faz-se relevante atentar a um conjunto de fatores: ambiente que comemos (local, estrutura, entorno), as relações sociais estabelecidas (os atores envolvidos e a convivência entre eles), os equipamentos disponíveis (utensílios e materiais), a quantidade e qualidade dos alimentos que são produzidos, o que comemos e para que comemos (questões biológicas/fisiológicas, psicológicas e econômicas, ideologias, crenças, culturas).

De acordo com as merendeiras das escolas públicas do município de Guarulhos (SP), e ao encontro dos resultados de outras pesquisas, torna-se essencial considerar na alimentação escolar, além dos aspectos nutricionais, os determinantes das práticas dos profissionais envolvidos nesse contexto, $\mathrm{O}$ comportamento alimentar das crianças e também o ambiente em que todo esse processo ocorre.

As percepções acerca da alimentação escolar para esses profissionais estão centradas em duas categorias: no alimento ofertado, a preocupação com o cardápio e qualidade dos gêneros que o compõem, e na estrutura disponibilizada para a preparação desses alimentos. Entende-se que essas concepções são frutos das funções exercidas no âmbito escolar, no seu entorno, focado nas atividades operacionais da alimentação, em produzir e distribuir refeições adequadas nutricionalmente e que satisfaça a criança quanto ao paladar. Porém, apesar destes profissionais estarem fortemente associados às funções de preparar e distribuir as refeições, frente à incorporação das novas diretrizes do programa, sob o aspecto da educação, deve-se destacar seu potencial para atuação como um promotor de hábitos alimentares saudáveis, dada a sua proximidade das crianças no convívio escolar.

Verificou-se a potencialidade desses profissionais no contexto da alimentação escolar, uma vez que a entendem sob diferentes aspectos, que envolvem todo $\mathrm{o}$ processo de preparação dos alimentos até a preocupação em ofertar uma refeição que tenha aceitabilidade pelas crianças, além da clara preocupação com as condições do ambiente e estrutura física para que a alimentação ocorra de forma adequada. Por outro lado, alguns fatores observados surgem como entraves para outras representações da alimentação escolar, como a inexploração da possibilidade de se assumirem também como promotores da educação nutricional, influenciadores na construção dos hábitos alimentares dos escolares.

É indiscutível que as merendeiras assumem um papel importante na alimentação oferecida às 
crianças nas escolas, mas talvez possuam poucas oportunidades de interferir em algumas questões identificadas como inadequadas. A atuação desses profissionais em Guarulhos, como em outros locais, acabava se restringindo às ações operacionais, visto que outros atores e, principalmente, as próprias merendeiras, não percebiam o espaço existente para ampliar a sua atuação e envolvimento na educação nutricional no âmbito escolar.

\section{REFERÊNCIAS}

[1] Teo CRPA, Corrêa EM, Gallina LS, Fransozi C. Programa Nacional de Alimentação Escolar: adesão, aceitação e condições de distribuição de alimentação na escola. Nutrire: Rev Soc Bras Alim Nutr. 2009;34(3):165-85.

[2] Diez-Garcia RW. Mudanças alimentares: implicações práticas, teóricas e metodológicas. In: Diez-Garcia RW, Cervato-Mancuso AM (Org.). Nutrição e metabolismo: mudanças alimentares e educação nutricional. Rio de Janeiro: Guanabara Koogan; 2011. p. 3-17.

[3] Diez-Garcia RW. Representações sociais da alimentação e saúde e suas repercussões no comportamento alimentar. Physis. 1997;7(2):51-68.

[4] Quaioti TCB, Almeida SS. Determinantes psicobiológicos do comportamento alimentar: uma ênfase em fatores ambientais que contribuem para a obesidade. Psicol USP. 2006;17(4):193-211.

[5] Costa EQ, Lima ES, Ribeiro VMB. O treinamento de merendeiras: análise do material instrucional do Instituto de Nutrição Annes Dias - Rio de Janeiro (1956-94). Hist Cienc Saude-Manguinhos. 2002;9(3):535-60.

[6] Carvalho AT, Muniz VM, Gomes JF, Samico I. Programa de alimentação escolar no município de João Pessoa - PB. Brasil: as merendeiras em foco. Interface, Comunic, Saúde, Educ. 2008;12(27):823-34.

[7] Teo CRPA, Sabedot FRB, Schafer E. Merendeiras como agentes de educação em saúde da comunidade escolar: potencialidades e limites. Rev Espaço para Saúde. 2010;11(2):11-20.

[8] Instituto Brasileiro de Geografia e Estatística. Cidades@. Guarulhos - SP, 2006 [acesso em 26 jan 2008]. Disponível em: http://ibge.gov.br/cidadessat

[9] Westphal MF, Bógus CM, Faria MM. Grupos focais: experiências precursoras em programas educativos em saúde no Brasil. Bol Oficina Sanit Panam. 1996;120(6):472-82.
[10] Carlini-Cotrim B. Potencialidades da técnica qualitativa grupo focal em investigações sobre abuso de substâncias. Rev Saúde Públ. 1996;30(3):285-93.

[11] Iervolino AS, Pelicioni MCF. A utilização do grupo focal como metodologia qualitativa na promoção da saúde. Rev Esc Enf USP. 2001;35(2):115-21.

[12] Nogueira-Martins MCF, Bógus CM. Considerações sobre a metodologia qualitativa como recurso para o estudo das ações de humanização em saúde. Saúde Soc. 2004;13(3):44-57.

[13] Munari DB, Esperidião E, Medeiros M, Garcia CM. Considerações teóricas e técnicas da utilização do grupo na investigação científica. Rev Enferm UERJ. 2008;16(1):11318.

[14] Bardin L. Análise de conteúdo. Lisboa: Edições 70; 1988.

[15] Minayo MCS. O desafio do conhecimento: pesquisa qualitativa em saúde. 8o ed. São Paulo: Hucitec; 2004.

[16] Santos LMP, Santos SMC, Santana LAA, Henrique FCS, Mazza RPD, Santos LAS, Santos LS. Avaliação de políticas públicas de segurança alimentar e combate à fome no período 1995-2002. Programa Nacional de Alimentação Escolar. Cad Saúde Pública. 2007;23(11):2681-93.

[17] Brasil. Ministério da Educação. Fundo Nacional de Desenvolvimento da Educação. Alimentação Escolar. Lei no 11.947, de 16 de junho de 2009. Dispõe sobre o atendimento da alimentação escolar do Programa Dinheiro Direto na Escola aos alunos da educação básica, altera as Leis no 10.880 , de 9 de junho de 2004, e dá outras providências [acesso em 18 ago 2011]. Disponível em: http://www.fnde.gov.br/index.php/programasalimentacao-escolar

[18] Mascarenhas JMO, Santos JC. Avaliação da composição nutricional e custos da alimentação escolar da rede municipal de Conceição do Jacuípe/BA. Sitientibus-Feira de Santana. 2006;35:75-90.

[19] Martins RCB, Medeiros MAT, Ragonha GM, Olbi JH, Segatti MEP, Osele MR. Aceitabilidade da alimentação escolar no ensino público fundamental. Rev Saúde. 2004;6(13):71-8.

[20] Valeriani TSM. A gestão escolarizada do Programa Escolar do Estado do Goiás [tese]. Piracicaba: Escola Superior de Agricultura "Luiz de Queiroz", Universidade de São Paulo; 2011. 126 p. 
[21] Brasil. Ministério da Educação. Fundo Nacional de Desenvolvimento da Educação. Alimentação Escolar. Portaria Interministerial no 1.010, de 8 de maio de 2006. Institui as diretrizes para a Promoção da Alimentação Saudável nas escolas de educação infantil, fundamental e nível médio das redes públicas e privadas, em âmbito nacional [acesso em 18 ago 2011]. Disponível em: http://www.fnde.gov.br/index.php/ae-legislacao

[22] Vieira MNCM, Ferriani MGC, Gomes R, Santos GVB, Marchi EMM. Gestão de um programa de alimentação escolar em um município paulista. Seg Alim Nutr. 2008;15(1):29-48.

[23] Spinelli MAS, Canesqui AM. Descentralização do Programa de Alimentação Escolar em Cuiabá: 1993-1996. Rev Nutr. 2004;17(2):151-65.

[24] Bezerra JAB. Alimentação e escola: significados e implicações curriculares da merenda escolar. Rev Bras Educ. 2009;14(40):103-15

[25] Costa EQ, Ribeiro VMB, Ribeiro ECO. Programa de Alimentação Escolar: espaço de aprendizagem e produção de conhecimento. Rev Nutr. 2001;14(3):225-29.

[26] Brasil. Ministério da Educação. Fundo Nacional de Desenvolvimento da Educação. Alimentação Escolar. Alimentação Escolar, 2011 [acesso em 18 ago 2011]. Disponível

http://www.fnde.gov.br/index.php/programasalimentacao-escolar

[27] Rotenberg S, Vargas SD. Práticas alimentares e o cuidado da saúde: da alimentação da criança à alimentação da família. Rev Bras Saúde Matern Infant. 2004;4(1):85-94.

[28] Toral N, Slater B. Abordagem do modelo transteórico no comportamento alimentar. Ciênc Saúde Colet. 2007;12(6):1641-50.

[29] Silva ACA, Telarolli Junior R, Monteiro MI. Analisando conhecimentos e práticas de agentes educacionais e professoras relacionadas à alimentação infantil. Ciênc Educ. 2010;16(1):199-214. 